\title{
Roles of Motivation, Opportunity, Ability, and Trust in the Willingness of Farmers to Adopt Green Fertilization Techniques
}

\author{
Qiusheng Li, Fang Zeng, Hao Mei, Tianqi Li and Dasheng Li * \\ College of Economics and Management, South China Agricultural University, Guangzhou 510642, China; \\ yumi2018@stu.scau.edu.cn (Q.L.); zengfang91@stu.scau.edu.cn (F.Z.); meihao3721@163.com (H.M.); \\ litianqi0806@outlook.com (T.L.) \\ * Correspondence: dshli@scau.edu.cn
}

Received: 29 October 2019; Accepted: 1 December 2019; Published: 4 December 2019

\begin{abstract}
Green fertilization technologies such as the formula fertilization technology and the water and fertilizer integration technology are important technologies to realize fertilizer reduction and replacement. To explore the willingness of farmers to adopt those technologies and its driving path, can help to improve soil quality and promote the sustainable development of agriculture. In this paper, trust is incorporated into the theoretical framework of motivation, opportunity, ability (MOA). Based on the questionnaire survey data of citrus farmers in Guangdong and Jiangxi provinces in China, the logical relationship of farmers' willingness to adopt green fertilization technology is analyzed from four aspects of adoption motivation, adoption opportunity, ability (technical operation ability and ant risk ability), and trust by using a structural equation model. The results showed that adoption motivation, adoption opportunity, technical operation ability, and anti-risk ability had significant positive direct effects on adoption willingness, which were $0.610,0.381,0.491$, and 0.297, respectively. Trust had an indirect effect, which was 0.191 . From the results of cross-group analysis, it can be seen that farmers' participation in organizations or contracts signed will strengthen the influence of adoption opportunity, technical operation ability and adoption motivation on adoption willingness. However, the influence of the anti-risk ability on adoption willingness was strengthened by the non-participation or non-contract peasant household groups.
\end{abstract}

Keywords: green fertilization technology; adoption willingness; motivation; opportunity; technical operation ability; anti-risk ability; trust; sustainable agricultural development; structural equation model

\section{Introduction}

The excessive application of chemical fertilizers is one of the main sources of agricultural non-point source pollution [1,2], and it is also the main cause of soil fertility decline, posing a serious threat to the sustainable development of agriculture in China [3,4]. Since 2015, many fertilizer reduction and replacement policies, such as zero-growth action of chemical fertilizer and the project of organic fertilizer instead of chemical fertilizer in fruits, vegetables, and tea cultivation, have been gradually implemented and achieved certain results [5]. According to China's National Bureau of Statistics, the amount of fertilizer used in 2018 was 56.53 million tons, showing negative growth for three consecutive years and 3.69 million tons less than 2015, a decrease of 6.1 percent. However, the application amount of chemical fertilizer for cash crops such as vegetables, fruits and tea in smallholders is still high, and the green fertilization technology adoption rate is low. Transforming small farmers' production methods, using formula fertilization technology, water and fertilizer integration technology 
is considered to be an effective means to improve soil quality. Hence, understanding the determinants of smallholders' technology adoption willingness has clear implications for agricultural and environmental policy design.

The literature has already investigated the factors explaining the adoption willingness of green fertilization technology. Many scholars have provided insights on socioeconomic factors when green fertilization technology adoption willingness was analyzed, and these factors mainly include resource endowment [6,7], characteristics of farmers [8-10], technical factors [11], institutional and environmental factors $[12,13]$. However, socioeconomic factors have already been found to explain only modest parts of variances when referring to pro-environmental behavioral intention [14]. Dominated by the motive-opportunity-ability theory, the discussion of the predictors of pro-environmental behavioral intention has strongly promoted the idea that the adoption willingness of green technology is an outcome of sociopsychological factors $[15,16]$.

When it comes to whether individuals are willing to adopt green fertilization techniques, adopting motivation, adopting opportunities and abilities are considered to be key psychosocial factors in adoption willingness. The promotion of green fertilization technology is government-led and often has greater externalities. As the most direct micro-practice individuals of this policy, farmers' sociopsychological factors such as trust in the government will also directly affect farmers' adoption willingness. Hence, this research aims to incorporate trust into the MOA theory, comprehensively analyze the influences and driving paths of motivation, opportunity, ability, and trust on farmers' green fertilization technology adoption. In addition, this paper attempts to group farmers according to whether to join an organization or to sign a contract, so as to further discuss the differences of farmers' willingness to adopt a green fertilization technology.

This study focuses on the relationship between sociopsychological factors (e.g., motivation, opportunity, technical operation ability, anti-risk ability, and trust) and adoption willingness. Based on micro-survey data from 426 citrus farmers in Guangdong and Jiangxi provinces in China, a structural equation model (SEM) was used to explore the driving path of citrus farmers' green fertilization technology adoption willingness. From a citrus farmer perspective, citrus production usually entails more fertilizer investment, implying that fertilization reduces and replacement might be more complex and available.

This paper contributes to the existing literature in two respects. Firstly, from the perspective of psychological factors, we incorporate trust into the MOA theoretical analysis framework to analyze farmers' willingness to apply green fertilization techniques, and divide their abilities into technical operational capabilities and anti-risk capabilities, so as to more clearly analyze the driving path of motivation, opportunity, ability, and trust to farmers' adoption willingness. Secondly, the farmers were divided into groups from the two aspects of organizational participation and contract signing, and the differences of willingness to adopt green fertilization technology among farmers were analyzed across groups, so as to better understand the regulating effect of organizational participation and contract signing on farmers' adopt intention.

The remaining sections of this paper are structured as follows. Section 2 discusses green fertilization techniques in China. Section 3 outlines the theoretical analysis framework and estimation strategies. Section 4 provides the data sources and descriptive statistics for sociopsychological factors. Section 5 discusses the SEM results by estimating the direct and indirect affections of latent variables. Section 6 demonstrates the conclusions and policy implications.

\section{Green Fertilization Techniques in China}

Chemical fertilizer can effectively improve the yield per unit area of crops, and its wide application has played an important role in ensuring China's food security and supply of important agricultural products [4]. Meanwhile, the nation is experiencing exacerbated water and soil pollution problems [13]. In order to reduce the negative impact of chemical fertilizer application on the environment, China 
has accelerated the promotion of green fertilization technologies, which include formula fertilization technology, water and fertilizer integration technology, etc.

The project for the use of organic fertilizer instead of chemical fertilizer in fruits, vegetables, and tea cultivation was proposed by the Ministry of Agriculture and Rural Affairs of China at the end of 2017. This project selected 32 citrus demonstration counties in the southern provinces of China to promote green fertilization technologies such as testing soil for formulated fertilization technology and water and fertilizer integration technology. The reason why fruit is selected as a crop promoted by green fertilization technology is that the excessive application of fertilizer in fruit production is serious [5], and organic fertilizer can significantly improve the appearance and taste of the fruit. It should be pointed out that organic fertilizers replace chemical fertilizers in the project refers to the combination of organic and inorganic materials through rational utilization of organic nutrient resources and the replacement of some chemical fertilizers with organic fertilizers. It is not a complete replacement.

The commercial organic fertilizer, which is the organic fertilizer obtained from animal manure, such as pig manure, chicken manure, etc. has been sterilized, had heavy metals and other substances that pollute the environment removed, and is produced by local fertilizer production enterprise in cooperation with large-scale farms. Since agricultural production and operation organizations can provide production, sales, and technical services to farmers, local governments trying to improve the use of commercial organic fertilizer by farmers through cooperatives, agricultural enterprises and other agricultural production and operation organizations, and agricultural technology extension stations provide technical support for farmers' access to technical training courses and related technical services. Hence, in the green fertilization technology promotion system, government departments can directly provide technical services to farmers, and can also provide technical services to farmers through agricultural production and operation organizations.

\section{Conceptual Framework and Estimation Strategies}

\subsection{Theoretical Framework and Research Hypotheses}

The motivation, opportunity, ability (MOA) theory is a classical theory that discusses psychological factors in organizational theory. It holds that individual decision-making behavior is significantly affected by motivation, opportunity and ability [17]. As a decision-maker of agricultural technology adoption, farmers' behaviors are driven to a certain extent by motivation, opportunity, and ability. At the same time, current research shows that trust can play an important role in reducing transaction costs and reducing operating costs of the system, and is an important path affecting farmers' behavior $[16,18,19]$. Therefore, this paper incorporated trust into MOA theory to build an analysis framework of farmers' willingness to adopt green fertilization technology and its driving factors.

(1) Motivation is the internal driving force that pushes an individual to engage in certain activities and move in one direction [20]. It usually does not change. Instead, it may increase or decrease. In this paper, motivation is defined as the driving force of farmers' willingness to adopt green fertilization technology. The decision of farmers' technology adoption is driven by internal demand and stimulated by external incentives. A good agricultural production environment and high quality agricultural products are an important internal demand of farmers. When farmers realize that excessive fertilization will cause soil pollution and affect the quality of agricultural products, they may use green fertilization technology to avoid these problems, so that their needs will be met. At this time, the willingness of farmers to adopt green fertilization technology has been enhanced. Technical incentives are an important manifestation of external incentives, and rational smallholders' decisions always pursue the maximization of benefits or the minimization of costs. In the long run, the adoption of green fertilization technology will reduce soil pollution and improve the quality of agricultural products, which will help farmers to increase their income. When farmers maintain a positive attitude, their willingness to adopt green fertilization technology will increase. Therefore, the adoption motivation 
has a positive correlation with the adoption willingness. In consequence, the following hypothesis is proposed:

Hypothesis 1a (H1a). The adoption motivation positively influences farmers' willingness to adopt green fertilization technology.

(2) Opportunity refers to the favorable situation faced by an individual within a certain period of time. Different situations may have different possibilities for the same behavior, and this difference represents a difference in opportunity [20]. In this paper, opportunity refers to the situation that is conducive to the adoption of green fertilization technology by farmers. Due to the obvious positive externalities of the green fertilization technology, the government plays a very important role in the promotion of the technology and needs to provide convenient conditions to promote the diffusion of the technology. These conveniences include services such as information, technical guidance, and the purchase of agricultural supplies. The stronger the administrative capacity of the government and the more convenient the conditions provided, the more likely the farmers will have a deeper understanding of the value and feasibility of green fertilization technology, which will help them to improve their willingness to adopt it. Therefore, the hypothesis can be proposed as following:

Hypothesis 2a (H2a). Adoption opportunities positively affect farmers' willingness to adopt green fertilization technologies.

(3) Ability refers to the potential of individual decision making and the confidence needed, that is, the knowledge level, technical level, and material resources needed to realize decision making [20]. In this paper, ability mainly refers to whether the resource endowment of farmers can deal with the difficulties in green fertilization technology operation and resist the risks in green agricultural production. Technical operation ability is an important aspect that farmers consider. Green fertilization technology threshold requirements are higher, if the technology is poorly mastered, will affect the growth and development of crops, resulting in reduced production. The technical operation capability is not only reflected in the early technical study, but also in the solution of the problems in the implementation process. In the absence of corresponding capabilities, even if farmers have strong motivation to adopt, the possibility of adopting technology will be low. In addition, due to the high risks inherent in agricultural production and the uncertainty of the application of green production technology, farmers should first consider whether they have sufficient anti-risk ability when adopting technology. Only when he realizes that he has the anti-risk ability of the technology will the farmer adopt the technology. Hence, the following hypothesis is proposed:

Hypothesis 3a (H3a). Technical operational ability positively affects farmers' willingness to adopt green fertilization technology.

Hypothesis $\mathbf{3 b} \mathbf{b} \mathbf{H} \mathbf{3} \mathbf{b})$. The anti-risk ability is positively affecting the willingness of farmers to adopt green fertilization technology.

Based on the MOA theoretical analysis above, this study assumes that the motivation, opportunity and ability of farmers to adopt green fertilization technology are the important factors affecting the willingness of farmers to adopt green fertilization technology. At the same time, there are also interactions between adoption motivation, adoption opportunity and capability (technical operational capability, anti-risk capability) [21]. The stronger the motivation is, the more active the farmers will be in learning about green fertilization technology, which is more conducive to the improvement of technical operation ability and anti-risk ability. The increase of adoption opportunities makes farmers more aware of the advantages of green fertilization technology, which is conducive to the formation of adoption motivation and trust in the government. The increase of adoption opportunities makes it 
relatively easy for farmers to solve the problems in the application of green fertilization technology and helps improve their technical operation ability and risk resistance ability. At the same time, with the improvement of technical operation ability, farmers' ability to resist risks will be enhanced. Based on the analysis above, this paper proposes the following hypotheses:

Hypothesis $\mathbf{1 b}$ (H1b). Adoption motivation has a positive impact on technical operational capability;

Hypothesis $\mathbf{2 b} \mathbf{( H 2 b ) . ~ A d o p t i o n ~ o p p o r t u n i t i e s ~ h a v e ~ a ~ p o s i t i v e ~ i m p a c t ~ o n ~ a d o p t i o n ~ m o t i v a t i o n ; ~}$

Hypothesis 2c (H2c). Adoption opportunities have a positive impact on technical operational capabilities;

Hypothesis 2d (H2d). Adoption opportunities have a positive impact on anti-risk capabilities;

Hypothesis 2e (H2e). Adoption opportunities have a positive impact on trust;

Hypothesis 3c (H3c). Technical operation ability has a positive effect on risk resistance ability.

(4) Trust refers to the confidence of an individual in the extent to which a trust target exhibits integrity, goodwill, ability, and predictable behavior [22]. In this paper, trust refers to the degree of farmers' trust in the government and agricultural extension departments. Some studies have pointed out that farmers' trust in the government has a direct impact on their willingness to participate in environmental protection, and can also indirectly influence their willingness to adopt through motivation and ability. Farmers often have greater distrust of new technologies. If they trust the government and the agricultural technology promotion department, they will increase their enthusiasm for learning technology and their knowledge of technical usefulness will be more comprehensive. Correspondingly, the adoption motivation of farmers is clearer, the technical operation ability is stronger, and the willingness to adopt technology will be enhanced. Based on the above analysis of the action mechanism of trust, this paper proposes the following hypothesis:

Hypothesis 4a (H4a). Trust has a positive effect on the adoption willingness;

Hypothesis $4 \mathbf{b}(\mathbf{H} 4 \mathbf{b})$. Trust has a positive effect on adoption motivation;

Hypothesis 4c (H4c). Trust has a positive effect on technical operational ability;

Hypothesis $4 \mathbf{d}$ (H4d). Trust has a positive effect on anti-risk ability.

The relationship between the theoretical framework model based on improved MOA theory and the research hypothesis constructed in this paper is shown in Figure 1. 


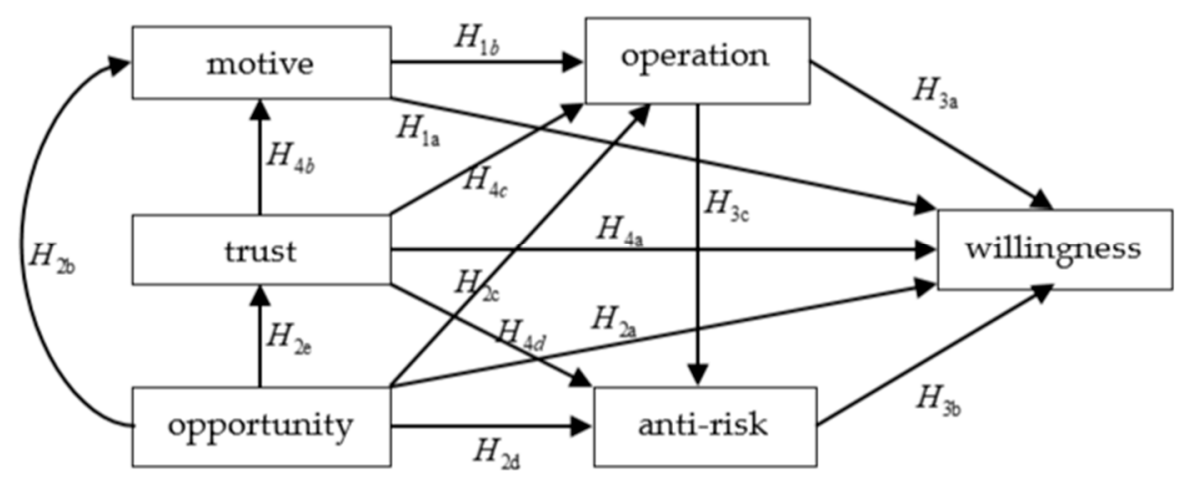

Figure 1. A decision model of adopting green fertilization technology for farmers based on improved motivation, opportunity, ability (MOA) theory.

\subsection{Estimation Strategies}

The primary interest of this study is to investigate the logical relationship between potential variables such as adoption motivation, adoption opportunity, technical operation ability, risk resistance ability and trust and farmers' willingness to adopt green fertilization technology. Because those variables are difficult to directly observe, and there may be multiple collinearity within these observable variables, it is not suitable to adopt Probit model and Logistic model. The structural equation model can not only solve the above problems well, but also measure the direct or indirect effects and obtain the key driving paths [23]. Therefore, this paper applies the SEM model for analysis, and the proposed measurement equation is as follows:

$$
\begin{aligned}
& \mathrm{X}=\wedge_{x} \xi+\delta \\
& \mathrm{Y}=\wedge_{y} \eta+\varepsilon
\end{aligned}
$$

where $\mathrm{X}$ is the vector of exogenous observation variable, which reflects the motivation, opportunity, ability, and trust degree of farmers to adopt green fertilization technology; and $\mathrm{Y}$ is the endogenous observation variable vector, which reflects the willingness of farmers to adopt green fertilization technology; $\wedge_{x}$ and $\wedge_{y}$ are the factor loadings of $X$ and $Y$ respectively; $\xi$ and $\eta$ represent the exogenous latent variables (i.e., adoption motivation, adoption opportunity, technical operation ability, anti-risk ability, and trust) and endogenous latent variables (i.e., adoption willingness) respectively; $\delta$ and $\varepsilon$ represent the measurement error of the explicit variable. In addition, $\varepsilon$ is not related to $\eta, \xi$ and $\delta$, and $\delta$ is not related to $\xi \eta$ and $\varepsilon$.

Based on measurement of the Equations (1) and (2), a structural equation model between exogenous and endogenous latent variables was constructed:

$$
\eta=B \eta+\Gamma \xi+\zeta
$$

where $B$ and $\Gamma$ represent the coefficient matrix of endogenous and exogenous latent variables, and $\zeta$ is the random error term of the structural equation. 


\section{Data and Descriptive Statistics}

\subsection{Data Source and Sampling Methods}

The data used in the present study were collected by the research team through a field survey of citrus farmers between May and July 2019 in Guangdong and Jiangxi provinces in China. The selected investigators were trained first, and then pre-investigated to allow them to understand the questionnaire accurately. Finally, face-to-face interviews were conducted with the citrus farmers. The field survey collected detailed information about respondents' citrus production operations and citrus sales details as well as organizational participation.

A multistage sampling procedure was used to collect data. First, Guangdong and Jiangxi provinces were purposively selected due to the intensive citrus production in these provinces. Second, we selected representative counties with significant citrus output, and they are the model counties of organic fertilizer instead of chemical fertilizer in fruits, vegetables and tea cultivation in each province. In particular, Meixian district and Huidong County in Guangdong and Xinfeng County in Jiangxi were selected. Third, six to five townships were randomly selected in each county/district, and these towns have taken into account whether the organic fertilizer replaces chemical fertilizer core demonstration zone and the non-core demonstration zone. Fourth, two to three villages affiliated to each town in the selected district were randomly selected. Finally, around 10 households including both participated organization farmers and non-participated in each village were randomly selected. Overall, 16 townships were randomly selected in the three counties, and 450 sample households were selected for the interview, 24 invalid questionnaires were excluded, and 426 actual questionnaires were valid, the effective rate of the questionnaire was $94.67 \%$. In addition, the sample includes 232 participated organization farmers and 194 non-participated. The questionnaire included household and farm-level characteristics, citrus production and operation details, green fertilization technology adoption details, and organization membership in 2018.

\subsection{Basic Characterization}

Considering our interests in studying the willingness of farmers to adopt green fertilization technology based on the improved MOA theory, we focus on the indicators of farmers' green fertilization technology adoption motivation, adoption opportunities, technical operation ability, anti-risk ability, trust and willingness to adopt. According to these indicators, a series of questions for observable variables are set in the questionnaire (see Table 1). The respondents were asked to answer the questions based on a five-point Likert scale (strongly disagree $=1$; disagree $=2$; neither agree nor disagree $=3$; agree $=4$; strongly agree $=5$ ). The adoption motivation and adoption opportunity scales are developed on the basis of the research results of $\mathrm{Wu}$ et al. and Blazy et al. [16,24]. The technical operational ability scale and the risk tolerance scale were improved by referring to the research results of Lambrecht et al. [25], and the trust scale was improved by referring to the research results of Prazan et al. [19]. The adoption willingness scale is derived from the relevant studies of Li [26].

The descriptive statistics showed that the average value of the four questions that represented the adoption motivation was 4.11 , indicating that citrus farmers had a certain motivation to adopt green fertilization technology. The average value of the three questions representing the adoption opportunity was 3.69, indicating that there are not many opportunities for farmers to obtain the technology, especially the government's poor performance in green fertilizer purchases. The mean values of the two questions of technical operation ability and anti-risk ability were 4.12 and 4.09, respectively, indicating that farmers have higher technical operation ability and anti-risk ability to adopt green fertilization technology. The average value of the two questions representing trust is 3.35, indicating that farmers have a low degree of trust in the government, especially in terms of the government's help in reducing losses; The mean value of the two questions representing the adoption willingness was 4.38 , indicating that farmers had a high demand for green fertilization technology. 
Table 1. Definition and descriptive statistics of observed variables.

\begin{tabular}{|c|c|c|c|}
\hline $\begin{array}{c}\text { Latent } \\
\text { Variables }\end{array}$ & Observed Variables and Definition & Mean & Standard Error \\
\hline \multirow{4}{*}{ motive } & $\begin{array}{l}\mathrm{m} 1 \text {-Adopting green fertilization technology is } \\
\text { beneficial to the improvement of soil quality }\end{array}$ & 4.44 & 0.705 \\
\hline & $\begin{array}{l}\mathrm{m} 2 \text {-Adopting green fertilization technology is } \\
\text { conducive to improving the quality of agricultural } \\
\text { products }\end{array}$ & 4.40 & 0.713 \\
\hline & $\begin{array}{l}\text { m3-Adopting green fertilization techniques can help } \\
\text { increase income }\end{array}$ & 3.86 & 0.726 \\
\hline & $\begin{array}{l}\text { m3-Adopting green fertilization techniques could help } \\
\text { save costs }\end{array}$ & 3.74 & 0.824 \\
\hline \multirow{3}{*}{ opportunity } & $\begin{array}{l}\text { o1-Government/organization has played a role in green } \\
\text { fertilization technology information services }\end{array}$ & 3.68 & 0.908 \\
\hline & $\begin{array}{l}\text { o2-Government/organization has played a role in } \\
\text { guiding green fertilization techniques }\end{array}$ & 3.79 & 0.913 \\
\hline & $\begin{array}{l}\text { o3-Government/organization has played a role in green } \\
\text { fertilizer purchases }\end{array}$ & 3.59 & 0.969 \\
\hline \multirow{2}{*}{ operation } & op1-Green fertilization techniques are easy to learn & 4.04 & 0.890 \\
\hline & $\begin{array}{l}\text { op2-I can solve the problems in the application of green } \\
\text { fertilization technology }\end{array}$ & 4.19 & 0.748 \\
\hline \multirow{2}{*}{ anti-risk } & ar1-The risks of green fertilization are controllable & 4.08 & 0.809 \\
\hline & $\begin{array}{l}\text { ar2-I can withstand the risks of green fertilization } \\
\text { technology }\end{array}$ & 4.10 & 0.792 \\
\hline \multirow[t]{2}{*}{ trust } & $\begin{array}{l}\mathrm{t} 1 \text {-The technical services brought by the } \\
\text { government/organization prompted me to trust the } \\
\text { technology }\end{array}$ & 3.62 & 0.777 \\
\hline & $\begin{array}{l}\text { t2-I believe that the government/organization can help } \\
\text { farmers mitigate losses when technical risks occur }\end{array}$ & 3.07 & 0.941 \\
\hline \multirow{2}{*}{ willingness } & w1-I am willing to adopt green fertilization techniques & 4.47 & 0.820 \\
\hline & $\begin{array}{l}\text { w2-I am willing to recommend green fertilization } \\
\text { technology to my neighbors. }\end{array}$ & 4.28 & 0.818 \\
\hline
\end{tabular}

\section{Empirical Results}

\subsection{Validation of Model}

Before the structural equation model is used for analysis, reliability and validity tests should be carried out on the data. Table 2 includes standardized factor loadings, Cronbach's $\alpha$, AVE, and CCR for each construct. All the loadings (see Figure A1) of items that remained to measure each variable were above 0.7 and larger than the cross-loadings, all items for each construct were confirmed to satisfy the criteria. Cronbach's $\alpha$ is an important index to check the internal consistency of latent variables, the Cronbach's $\alpha$ values for motive, opportunity, operation, anti-risk, trust, and willingness were 0.836 , $0.863,0.762,0.776,0.759$, and 0.852 , respectively; each construct was above 0.70 . The AVE values were between 0.5622 and 0.7431 , and all above 0.50 , indicating a high level of convergent validity [27]; and the CCR were between 0.764 and 0.870 , surpassing the suggested 0.70 minimum and indicating that the composite measurement items have sufficient internal consistency reliability [27]. In addition, the KMO Test value was 0.835 and the Bartlett's Test statistical value was 0.000 , indicating that the observed variable data had good validity and was suitable for factor analysis. Therefore, those tests show that this measurement model has a good convergent validity. 
Table 2 . The reliability and validity test.

\begin{tabular}{|c|c|c|c|c|c|}
\hline Latent Variables & Indicators & Standardized Factor Loadings & Cronbach's $\alpha$ & AVE & CCR \\
\hline \multirow{4}{*}{ motive } & $\mathrm{m} 1$ & 0.7668 & \multirow{4}{*}{0.836} & \multirow{4}{*}{0.5622} & \multirow{4}{*}{0.8369} \\
\hline & $\mathrm{m} 2$ & 0.7116 & & & \\
\hline & $\mathrm{m} 3$ & 0.7604 & & & \\
\hline & $\mathrm{m} 4$ & 0.7592 & & & \\
\hline \multirow{3}{*}{ opportunity } & o1 & 0.8471 & \multirow{3}{*}{0.863} & \multirow{3}{*}{0.6911} & \multirow{3}{*}{0.8697} \\
\hline & o2 & 0.8952 & & & \\
\hline & o3 & 0.7446 & & & \\
\hline \multirow{2}{*}{ operation } & op1 & 0.7840 & \multirow{2}{*}{0.762} & \multirow{2}{*}{0.6191} & \multirow{2}{*}{0.7647} \\
\hline & op2 & 0.7896 & & & \\
\hline \multirow{2}{*}{ anti-risk } & ar1 & 0.7916 & \multirow{2}{*}{0.776} & \multirow{2}{*}{0.6337} & \multirow{2}{*}{0.7758} \\
\hline & ar2 & 0.8005 & & & \\
\hline \multirow{2}{*}{ trust } & $\mathrm{t} 1$ & 0.8472 & \multirow{2}{*}{0.759} & \multirow{2}{*}{0.6228} & \multirow{2}{*}{0.7655} \\
\hline & $\mathrm{t} 2$ & 0.7265 & & & \\
\hline \multirow{2}{*}{ willingness } & w1 & 0.8362 & \multirow{2}{*}{0.852} & \multirow{2}{*}{0.7431} & \multirow{2}{*}{0.8525} \\
\hline & w2 & 0.8871 & & & \\
\hline
\end{tabular}

Note: $\mathrm{N}=426 ; \mathrm{AVE}=$ Average Variance Extracted; CCR = Composite Construct Reliability.

Before the initial model to be modified, cross-validation should be conducted [28,29]. Therefore, we used SPSS20.0 (IBM, New York, NY, USA) to randomly divide the original sample into two parts: a derivation sample and a cross validation sample. Then, two groups were established in AMOS, and the randomly divided sample data were imported to conduct multi-group analysis to obtain cross-validation results. The results (see Table 3) show that the hypothesis "Assuming model unconstrained to be correct" is accepted $(p>0.1)$. It is suggested that once a favored model is found, its fit can be assessed by using different data from the cross-validation sample. The cross-validation test indicates that the validity of the model is ductile and stable, which further demonstrates the validity of the model.

Table 3. The results of cross-validation test.

\begin{tabular}{cccc}
\hline Model & DF & CMIN & $p$ \\
\hline Measurement weights & 9 & 13.435 & 0.144 \\
Structural weights & 23 & 26.941 & 0.258 \\
Structural residuals & 29 & 30.642 & 0.383 \\
Measurement residuals & 44 & 40.230 & 0.634 \\
\hline
\end{tabular}

\subsection{The Results of SEM}

AMOS21.0 software (IBM, New York, NY, USA) was used to construct a structural equation model of the relationship among adoption motivation, adoption opportunity, technical operational ability, anti-risk ability, trust and adoption willingness. Before presenting the results for the structural equation model, we will first present the fitness test for the justification for the SEM. In this paper, absolute fit index, incremental fit index and parsimonious fit index are considered when evaluating the fitness of the model, so that a consensus can be reached on the acceptability or rejection of the model. Since AGFI is lower than 0.9 and CMIN/DF is higher than 3 in the initial model, the index was modified by adding a correlation of error terms, and obtaining the fitness index of modified model (see Table 4). The absolute fit index, incremental fit index, and parsimonious fit index of the modified model are all within the adapted standards [30], suggesting that the actual data fit well with the theoretical model constructed above. 
Table 4. Fitness test of SEM.

\begin{tabular}{ccccc}
\hline Fit Index & Test Indicators & Initial Model & Modified Model & Adapted Standards \\
\hline & RMR & 0.025 & 0.033 & $<0.05$ \\
Absolute Fit Index & RMSEA & 0.075 & 0.043 & $<0.05$ \\
& GFI & 0.922 & 0.961 & $>0.90$ \\
& AGFI & 0.877 & 0.937 & $>0.90$ \\
\hline & NFI & 0.919 & 0.958 & $>0.90$ \\
Incremental Fit Index & RFI & 0.888 & 0.941 & $>0.90$ \\
& IFI & 0.941 & 0.981 & $>0.90$ \\
& TLI & 0.918 & 0.973 & $>0.90$ \\
& CFI & 0.941 & 0.981 & $>0.90$ \\
\hline \multirow{4}{*}{ Parsimonious Fit Index } & PGFI & 0.584 & 0.601 & $>0.50$ \\
& PNFI & 0.665 & 0.684 & $>0.50$ \\
& PCFI & 0.681 & 0.701 & $>0.50$ \\
& CN & 426 & 426 & $>200$ \\
\hline
\end{tabular}

According to the data analysis in Table 5 and the results of the structural equation model in Figures 2 and 3 , the following results were obtained:

(1) The adoption motivation has a significant positive impact on the operational ability of farmers, and also has a significant positive impact on the adoption willingness. The results showed that both H1a and $\mathrm{H} 1 \mathrm{~b}$ were verified. It also shows that the adoption motivation influences the adoption willingness mainly through two paths: The first path is "motivation $\rightarrow$ willingness", that is, adoption motivation directly affects the adoption willingness, indicating that the stronger the adoption motivation of farmers, the higher their adoption willingness will be. The second path is " motivation $\rightarrow$ operation $\rightarrow$ willingness", that is, the adoption motivation is indirectly affected the adoption willingness through the technical operation ability, which confirms that the stronger the adoption motivation of farmers is, the stronger the operation ability is, thus contributing to the improvement of adoption willingness.

(2) The influence of adoption opportunity on adoption willingness, adoption motivation, and trust is significantly positive, among which adoption opportunity has the greatest influence on trust. The research hypotheses $\mathrm{H} 2 \mathrm{a}, \mathrm{H} 2 \mathrm{~b}$, and H2e have been verified. It can be seen from the results that the adoption opportunity mainly influences the adoption willingness in two ways: one is "opportunity $\rightarrow$ willingness", that is, the adoption opportunity directly affects the adoption willingness, indicating that the more adoption opportunities farmers have, the stronger their adoption willingness will be. The second path is "opportunity $\rightarrow$ motivation $\rightarrow$ willingness", that is, adoption opportunity indirectly affected adoption willingness through adoption motivation, which proves that the more adoption opportunities farmers have, and the stronger their adoption motivation will be, thus contributing to the improvement of adoption willingness. Therefore, with the increase of adoption opportunities, farmers' willingness to adopt green fertilization technology was significantly enhanced. At present, the government often improves the chances of adopting green fertilization technology by providing information, technology, and purchasing services for farmers. However, the survey results showed that among the sample farmers, the proportion of farmers who agreed that the government played a significant role in information, technology, and purchase of services was relatively low, which indicated that improving the socialized service ability of the government could greatly improve the chances for farmers to adopt green fertilization technology.

(3) Both technical operational ability and anti-risk ability have a significant positive impact on the adoption willingness, and the technical operational ability also has a significant positive impact on the adoption willingness of farmers by acting on the ability to resist risks. This indicates that improving the operational ability and anti-risk ability of farmers will help increase the willingness of farmers to adopt the green fertilization technology. The hypotheses H3a, H3b and H3c have been verified. It can be seen that reducing the risks in the process of adopting green fertilization technology 
and improving the technical operation ability of farmers will greatly enhance their willingness to adopt green fertilization technology. At present, the technical operation ability and anti-risk ability of farmers are relatively low, mainly because the application threshold of green fertilization technology is relatively high, which is difficult for farmers to master. In addition, the low household income level and imperfect supporting measures will increase the risk of green fertilization technology application, and the low knowledge level of most farmers will also hinder the improvement of farmers' technical operation ability. Therefore, even though government technical training and agricultural subsidies, the improvement of farmers' technical operation ability and risk resistance ability is still limited, it is difficult for the smallholders to adopt.

(4) Trust did not have a significant direct impact on the adoption willingness, and H4a was not verified. However, trust indirectly positively affected the adoption intention through operational ability, with a path coefficient of 0.285 , which indicated that enhancing the degree of trust in the government of farmers would help indirectly improve the willingness of farmers to adopt green fertilization technology. The research hypothesis $\mathrm{H} 4 \mathrm{c}$ proposed above has been verified. Therefore, the spread and application of green fertilization technology in China cannot be promoted without farmers' high trust in the government.

The total effect is the sum of the regression coefficients of all direct effects and indirect effects related to the latent variable in the path model. The strength of indirect effects is multiplied by the standard regression coefficients of direct effects between the two endpoint variables. In this model, the total effects of green fertilization technology adoption motivation, adoption opportunity, technical operation ability, anti-risk ability and trust on the willingness to adopt were $0.610,0.381,0.491,0.297$ and 0.259 , respectively. It can be seen that the adoption motivation is the most important factor affecting the willingness of farmers to adopt green fertilization technology, followed by technical operation ability and adoption opportunity.

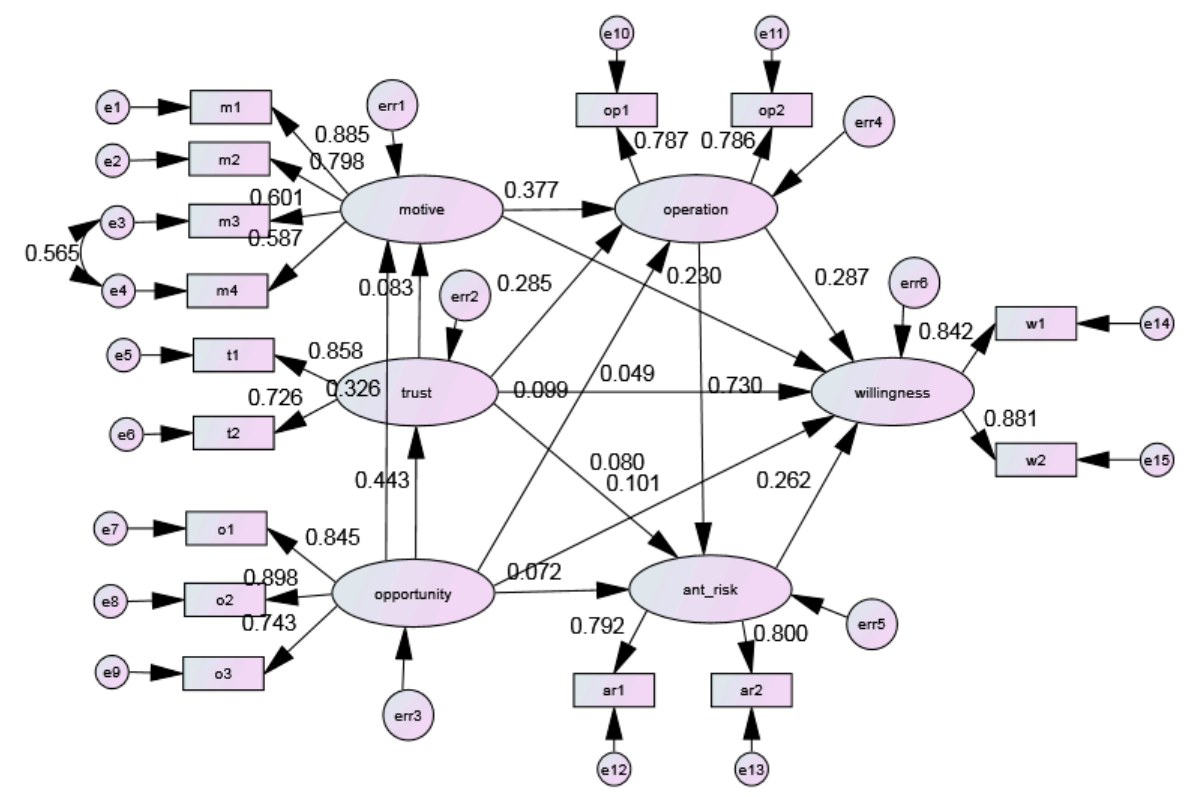

Figure 2. Standard estimates in the modified model. 
Table 5. Structural relations and the results of hypothesis test.

\begin{tabular}{ccc}
\hline Hypothesis & Standardized Regression Weights & Accept/Refuse \\
\hline trust $\leftarrow$ opportunity & $0.443^{* * *}$ & Accept \\
motive $\leftarrow$ trust & 0.083 & Refuse \\
motive $\leftarrow$ opportunity & $0.326^{* * *}$ & Accept \\
operation $\leftarrow$ trust & $0.285^{* * *}$ & Accept \\
operation $\leftarrow$ opportunity & 0.099 & Refuse \\
operation $\leftarrow$ motive & $0.377^{* * *}$ & Accept \\
anti-risk $\leftarrow$ trust & 0.080 & Refuse \\
anti-risk $\leftarrow$ operation & $0.730^{* * *}$ & Accept \\
anti-risk $\leftarrow$ opportunity & 0.072 & Refuse \\
willingness $\leftarrow$ trust & 0.049 & Refuse \\
willingness $\leftarrow$ anti-risk & $0.262^{* *}$ & Accept \\
willingness $\leftarrow$ operation & $0.287^{* * *}$ & Accept \\
willingness $\leftarrow$ motive & $0.230^{* * *}$ & Accept \\
willingness $\leftarrow$ opportunity & $0.101^{*}$ & Accept \\
\hline
\end{tabular}

Note: ${ }^{*}, * *$ and ${ }^{* * *}$ indicate significance at the $10 \%, 5 \%$, and $1 \%$ levels, respectively.

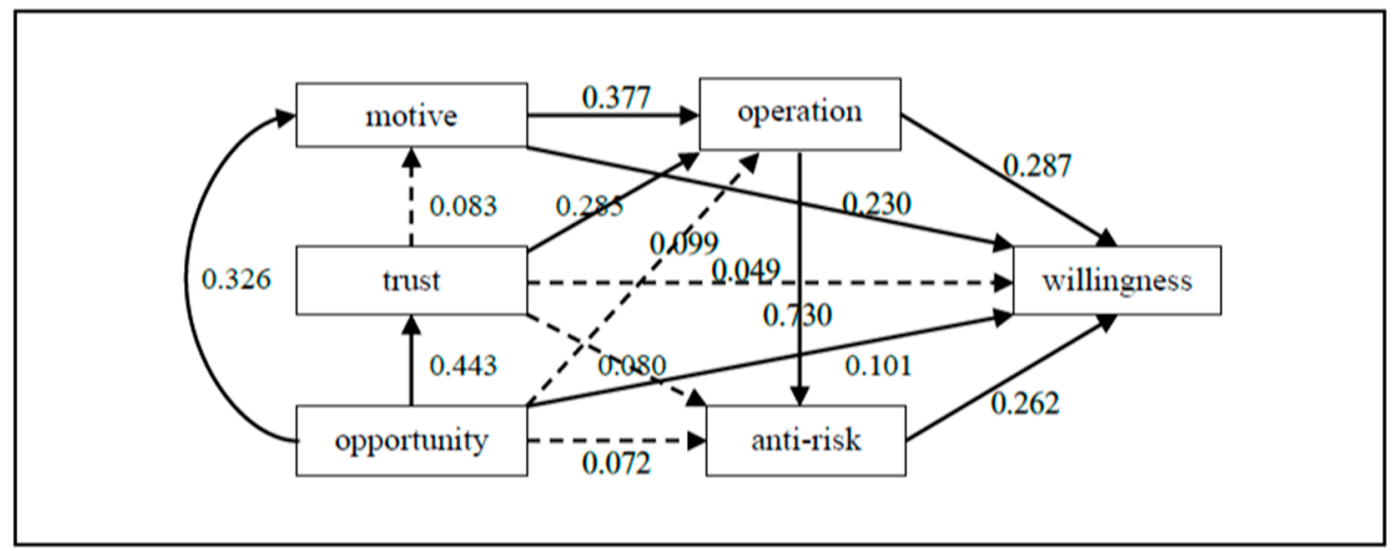

Figure 3. The driving path and coefficient estimation results. Note: The solid arrow indicates acceptance of the hypothesis; the dotted arrow represents a rejection of the hypothesis.

Existing research shows that cooperative participation and production and sales contract signing are beneficial for farmers to adopt green fertilization technology [31-33]. Therefore, a cross-group structural equation model was used in this paper to explore the willingness and driving path of different types of farmers to adopt green fertilization technology. The results of the cross-group structural equation model are shown in Table 6, and the indirect influence path is omitted. Except that the fitness index AGFI is less than 0.9 , but very close to 0.9 , the test indexes of the adjusted model all meet the requirements, and the model is generally capable of interpretation. According to the direct effects in the table, organizational participation and contract signing can regulate the positive effects of adoption opportunity, adoption motivation, technical operation ability and risk resistance on the willingness to adopt green fertilization technologies. In the group of farmers who participated in the organization or signed the contract, the adoption opportunity and technical operational capability had a significant positive impact on the adoption intention, but this path was not significant in the group of farmers who did not participate in the organization or signed the contract. Conversely, in non-participating or non-contracted farmer groups, anti-risk capabilities have a significant positive impact on adoption willingness, but the path is not significant in participating organizations or contracted farmer groups. In addition, adoption motivation had a significant positive effect on adoption intention in all the farmer groups. 
Table 6. Cross-group comparison results of structural equation models.

\begin{tabular}{|c|c|c|c|c|}
\hline \multirow{2}{*}{ Hypothesis } & \multicolumn{2}{|c|}{ Organization Member } & \multicolumn{2}{|c|}{ Signing Contract } \\
\hline & Non-Member & Member & Not Signed & Signed \\
\hline willingness $\leftarrow$ trust & 0.003 & 0.045 & 0.030 & 0.009 \\
\hline willingness $\leftarrow$ anti-risk & $0.534^{* * *}$ & 0.067 & $0.535^{* * *}$ & 0.060 \\
\hline willingness $\leftarrow$ operation & 0.147 & $0.295 *$ & 0.124 & $0.375^{* *}$ \\
\hline willingness $\leftarrow$ motive & $0.261^{* * *}$ & $0.234^{* *}$ & $0.215^{* * *}$ & $0.315^{* * *}$ \\
\hline willingness $\leftarrow$ opportunity & 0.006 & $0.187^{* *}$ & 0.018 & $0.196^{* *}$ \\
\hline CMIN/DF & \multicolumn{2}{|c|}{1.713} & \multicolumn{2}{|c|}{1.809} \\
\hline RMSEA & \multicolumn{2}{|c|}{0.041} & \multicolumn{2}{|c|}{0.044} \\
\hline GFI & \multicolumn{2}{|c|}{0.929} & \multicolumn{2}{|c|}{0.926} \\
\hline AGFI & \multicolumn{2}{|c|}{0.886} & \multicolumn{2}{|c|}{0.890} \\
\hline CFI & \multicolumn{2}{|c|}{0.962} & \multicolumn{2}{|c|}{0.958} \\
\hline TLI & \multicolumn{2}{|c|}{0.947} & \multicolumn{2}{|c|}{0.941} \\
\hline
\end{tabular}

Notes: ${ }^{*}, * *$ and ${ }^{* * *}$ indicate significance at the $10 \%, 5 \%$, and $1 \%$ levels, respectively. Organizational members refer to members of agricultural production and operation organizations, mainly members of cooperatives or agricultural enterprises. Contract signing refers to whether a production contract is signed between farmers and cooperatives or agricultural enterprises.

\section{Conclusions and Policy Implications}

This study attempted to incorporate trust into MOA theory, and applied SEM model to study the influence of motivation, opportunity, ability and trust on farmers' willingness to adopt green fertilization technology by using survey data of citrus farmers in Guangdong and Jiangxi province in China. The results showed that the adoption motivation, adoption opportunity, technical operation ability, and anti-risk ability can significantly affect farmers' willingness to adopt green fertilization technology, while trust has a significant indirect effect, which indirectly affects farmers' willingness to adopt green fertilization technology through technical operation ability. The total effects of adoption motivation, adoption opportunity, technical operation ability and risk resistance on the adoption willingness were $0.610,0.381,0.491$ and 0.297 , respectively, and the indirect effect of trust was 0.191 . The results show that sociopsychological factors have a marked effect towards green technology adoption, which confirm the results found in previous studies [15,16,18,34].

Meanwhile, this conclusion confirms the effectiveness of MOA theory in changing farmers' willingness to adopt green fertilization technology, and also indicates that farmers' trust in the government can effectively promote technology diffusion. In this sense, the findings imply that local government and environmentalists must increase support for more technology acquisition opportunities, and government science and technology extension personnel should try to form a regular, multi-modal technical guidance model to solve the practical problems encountered by farmers in the application of green fertilization technology. Relevant departments should speed up the research and development of green fertilization technology and provide farmers with economic, convenient, and practical technologies. It is also necessary to provide technical subsidies and support for farmers to adopt green technologies to enhance farmers' trust in the government.

In particular, the cross-group analysis showed that the adoption motivation had a larger impact on the adoption intention of the contract signing farmers, while the adoption opportunity and technical operational ability had a stronger impact on the adoption willingness of farmers who participated in organizing and signing contracts. Moreover, the anti-risk ability had a stronger impact on the adoption willingness of farmers who did not participate in the organization and those who did not sign the contract. This conclusion shows that organizational participation and contract signing have a regulating effect on farmers' willingness to adopt green fertilization technology, and the influence path of adopting willingness can be adjusted through them. It confirms the evidence found in literature for replace chemical fertilizers with organic fertilizers [33]. Thus, more technical access opportunities should be provided to the farmers who participating in the organization or the signing the contract, 
and insurance should incorporate into the scope of the risk compensation system to enhance the ability of non-participating organizations and non-contracted farmers to resist risks.

Notably, this study has limitations. First, this paper only focuses on the influence of psychological factors on the willingness of farmers to adopt green fertilization technology. Future research should focus on other factors that directly or indirectly contribute to the sustainability of green fertilization technology. Second, the cross-sectional data led to a statistically ambiguous correlation between the constructs of the study. This study has, thus, specifically examined the relationships of association rather than causality. Further research should analyze the causal relationship between these variables. Therefore, a longitudinal study of the temporal dynamics between motivation, opportunity, ability, trust, and willingness would be valuable.

Author Contributions: Investigation, Q.L., H.M.; Methodology, Q.L., D.L.; Writing-original draft, Q.L.; Writing-review \& editing, Q.L., F.Z., and T.L., All authors were committed to improving this paper and are responsible for the viewpoints mentioned in this work.

Funding: This research was supported by the National Social Science Foundation of China, grant number 14BJY122 and The Graduate Student Overseas Study Program of South China Agricultural University, grant number 2019LHPY007.

Acknowledgments: We are thankful for the financial support of the National Social Science Foundation of China (14BJY122) and The Graduate Student Overseas Study Program of South China Agricultural University (2019LHPY007). We express our appreciation to the anonymous referees and editors of the journal for their constructive comments and suggestions.

Conflicts of Interest: The authors declare no conflicts of interest.

\section{Appendix A}

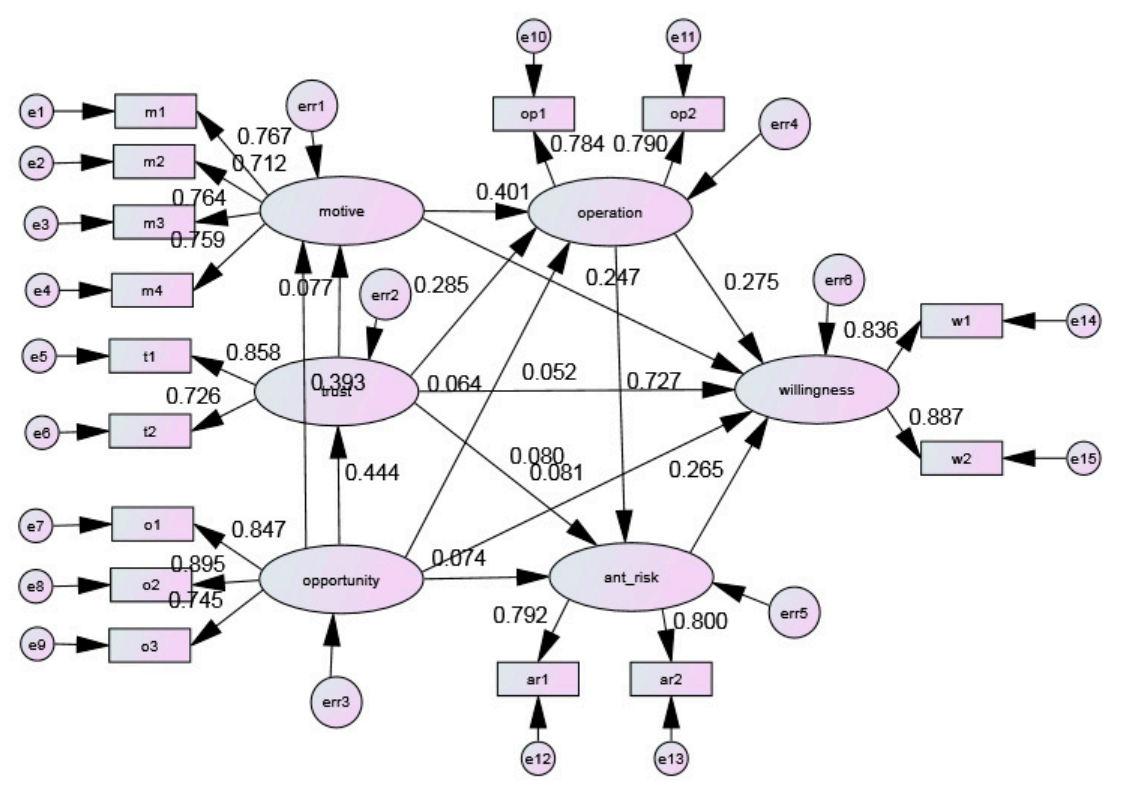

Figure A1. Standardized factor loadings of the indicators in initial model.

\section{References}

1. He, H.; Zhang, L.; Li, Q. Study on fertilization behavior of farmers and non-point source pollution in agriculture. J. Agrotech. Econ. 2006, 2-10. [CrossRef]

2. Zhang, W.; Wu, S.; Ji, H.; Kolbe, H. Estimation of agricultural non-point source pollution in China and the alleviating strategies I. Estimation of agricultural non-point source pollution in China in early 21 century. Sci. Agric. Sin. 2004, 37, 1008-1017.

3. Jin, S.; Zhang, H.; Wu, N. Evaluation on the implementation of zero-growth action of chemical fertilizer and pesticide use of 2016. Environ. Prot. 2018, 46, 45-49. 
4. Yang, Y.; Luo, X. The impact of reduction and replacement policy on famers' willingness to adopt the organic fertilizer: An empirical analysis based on the survey data of tea growers in Hubei. J. Agrotech. Econ. 2018, 77-85. [CrossRef]

5. Sun, R. Production of green agriculture: An evaluation of the process of reducing chemical fertilizer and replacing with organic fertilizer. Chongqing Soc. Sci. 2019, 33-43. [CrossRef]

6. Abdulai, A.; Huffman, W. The adoption and impact of soil and water conservation technology: An endogenous switching regression application. Land Econ. 2014, 90, 26-43. [CrossRef]

7. Hayati, D.; Abadi, B.; Movahedi, R.; Heidari, M. An empirical model of factors affecting farmers' participation in natural resources conservational programs in Iran. ID-20093050058. J. Food Agric. Environ. 2009, 7, 201-207.

8. Cui, X.; Cai, Y.; Zhang, A. The production willingness and influencing factors of farmers to reduce the application amount of chemical fertilizers and pesticides. Rural Econ. 2011, 11, 97-100.

9. Gu, J.; Chen, B.; Xu, C.; Lu, J. Study on the impact of rural household's factors towards the new technology adoption on rice production: Based on rural households surveys in Jiangsu province. J. Yangzhou Univ. (Agric. Life Sci. Ed.) 2007, 57-60. [CrossRef]

10. Traoré, N.; Landry, R.; Amara, N. On-farm adoption of conservation practices: The role of farm and farmer characteristics, perceptions, and health hazards. Land Econ. 1998, 74, 114-127. [CrossRef]

11. Gao, J.; Peng, C.; Shi, Q. Study on the high chemical fertilizers consumption and fertilization behavior of small rural household in China: Discovery from 1995-2016 National Fixed Point Survey Data. Manag. World 2019, 35, 120-132.

12. Karidjo, Y.B.; Wang, Z.; Boubacar, Y.; Wei, C. Factors Influencing Farmers' Adoption of Soil and Water Control Technology (SWCT) in Keita Valley, a Semi-Arid Area of Niger. Sustainability 2018, 10, 288. [CrossRef]

13. Li, Y.; Zhang, W.; Ma, L.; Huang, G.; Oenema, O.; Zhang, F.; Dou, Z. An analysis of China's fertilizer policies: Impacts on the industry, food Security, and the environment. J. Environ. Qual. 2013, 42, 972-981. [CrossRef] [PubMed]

14. Yuan, Y.; Nomura, H.; Takahashi, Y.; Yabe, M. Model of Chinese household kitchen waste separation behavior: A case study in Beijing city. Sustainability 2016, 8, 1083. [CrossRef]

15. Jiang, H.; Xu, L. Study on the main factors affecting farmers' willingness of agricultural product production safety. J. Anhui Agric. Sci. 2010, 38, 9256-9259.

16. Wu, X.; Zhang, J.; He, K.; Zhang, L. Farmer willingness to adopt rice straw returning technology and driving path. Resour. Sci. 2016, 38, 2117-2126.

17. Maclnnis, D.J.; Jaworski, B.J. Information processing from advertisements: Toward an integrative framework. J. Mark. 1989, 53, 1-23. [CrossRef]

18. He, K.; Zhang, J.; Zhang, L.; Wu, X. Interpersonal trust, institution-based trust and farmers' willingness to participate in environmental governance: A case study on the reutilization of agricultural waste. Manag. World 2015, 5, 75-88.

19. Prazan, J.; Theesfeld, I. The role of agri-environmental contracts in saving biodiversity in the post-socialist Czech Republic. Int. J. Commons 2014, 8, 1-25. [CrossRef]

20. Bagozzi, R.P.; Dholakia, U. Goal setting and goal striving in consumer behavior. J. Mark. 1999, 63, $19-32$. [CrossRef]

21. Devellis, R. Scale Development: Theory and Applications, Applied Social Research Methods; Sage Publications: Thousand Oaks, CA, USA, 2003; pp. 1-216.

22. Harrison McKnight, D.; Choudhury, V.; Kacmar, C. The impact of initial consumer trust on intentions to transact with a web site: A trust building model. J. Strateg. Inf. Syst. 2002, 11, 297-323. [CrossRef]

23. Wu, M. Structural Equation Modeling-Operation and Application of AMOS; Chongqing University Press: Chongqing, China, 2010.

24. Blazy, J.-M.; Carpentier, A.; Thomas, A. The willingness to adopt agro-ecological innovations: Application of choice modelling to Caribbean banana planters. Ecol. Econ. 2011, 72, 140-150. [CrossRef]

25. Lambrecht, I.; Vanlauwe, B.; Merckx, R.; Maertens, M. Understanding the Process of Agricultural Technology Adoption: Mineral Fertilizer in Eastern DR Congo. World Dev. 2014, 59, 132-146. [CrossRef]

26. Li, H. An empirical analysis of farmers' adoption willingness on cycle agricultural technology. China Rural Surv. 2012, 2, 28-36. 
27. Hair, J.F.; Hult, G.T.M.; Ringle, C.; Sarstedt, M. A Primer on Partial Least Squares Structural Equation Modeling (PLS-SEM); SAGE Publications: Thousand Oaks, CA, USA, 2016.

28. Breckler, S.J. Applications of covariance structure modeling in psychology: Cause for concern? Psychol. Bull. 1990, 107, 260-273. [CrossRef] [PubMed]

29. Cudeck, R.; Browne, M.W. Cross-Validation of Covariance Structures. Multivar. Behav. Res. 1983, 18, $147-167$. [CrossRef]

30. Byrne, B.M. Structural Equation Modeling with AMOS: Basic Concepts, Applications, and Programming (Second Edition); Routledge: New York, NY, USA, 2010.

31. Ma, W.; Abdulai, A.; Goetz, R. Agricultural Cooperatives and Investment in Organic Soil Amendments and Chemical Fertilizer in China. Am. J. Agric. Econ. 2018, 100, 502-520. [CrossRef]

32. Wossen, T.; Abdoulaye, T.; Alene, A.; Haile, M.G.; Feleke, S.; Olanrewaju, A.; Manyong, V. Impacts of extension access and cooperative membership on technology adoption and household welfare. J. Rural Stud. 2017, 54, 223-233. [CrossRef]

33. Wang, Y.; Zhu, Y.; Zhang, S.; Wang, Y. What could promote farmers to replace chemical fertilizers with organic fertilizers? J. Clean. Prod. 2018, 199, 882-890. [CrossRef]

34. Adnan, N.; Md Nordin, S.; Rahman, I.; Noor, A. Adoption of green fertilizer technology among paddy farmers: A possible solution for Malaysian food security. Land Use Policy 2017, 63, 38-52. [CrossRef]

(C) 2019 by the authors. Licensee MDPI, Basel, Switzerland. This article is an open access article distributed under the terms and conditions of the Creative Commons Attribution (CC BY) license (http://creativecommons.org/licenses/by/4.0/). 